\title{
Best vitelliform macular dystrophy: clinical case report
}

\author{
Virginija Asmoniene ${ }^{1}$, Andrea Breda Klobus ${ }^{2}$, Rasa Liutkeviciene ${ }^{2}$, Alvita Vilkeviciute ${ }^{*}$, Brigita Budiene ${ }^{1}$ and Loresa Kriauciuniene $^{1}$ \\ ${ }^{1}$ Lithuanian University of Health Sciences, Medicine Academy, Lithuania \\ ${ }^{2}$ Centogene GmbH, Lithuania
}

\begin{abstract}
We report a case of Best vitelliform macular dystrophy (BVD) in an 8-year-old boy complaining of reduced visual acuity in both eyes for several months. His bestcorrected visual acuity in the right eye was 0.6 and 0.3 in the left eye. Ophthalmoscopy of the right eye revealed a big yellow macular lesion surrounded by few smaller lesions with clear content and moderate edema in the central part of the retina (similar to BVD "scrambled egg" stage). In his left eye, we found a big round lesion with clear liquid boundary in the central part of the retina (similar to BVD pseudohypopyon stage). In the electro-oculogram Arden index of the right eye was 0.78 and 0.7 of the left eye (normal more than 1.8 (if <1.8; typical to BVD). We found a heterozygous mutation in exon 7 of the BEST1 gene (c.728A>T p.D243V), and conclude that the patient is very likely to suffer from BVD due to a mutation in the BEST1 gene. There were no detected mutations of the BEST1 gene in patient's both parents. We only observe this patient every 6 months because there is no causal treatment for this disorder yet.
\end{abstract}

\section{Introduction}

Best vitelliform macular dystrophy (BVD) is named after the German ophthalmologist Friedrich Best, who described a family with a history of early-onset macular degeneration in 1905 [1]. Best disease is known as vitelliform (egg-yolk like) macular dystrophy because of the yellow lesions in the macula associated with the condition [2]. It has much in common with age-related macular degeneration, which is the main culprit of vision loss in the elderly Western population [3]. Best vitelliform macular dystrophy is inherited in an autosomal dominant manner with variable expression [4]. Usually lesions are bilateral, but can be unilateral. The yellow material is gradually resorbed over time, leaving atrophic area of the retinal pigment epithelium, and often followed by subretinal fibrosis. At the beginning of the disease patients have normal vision. Later, central visual acuity decreases and metamorphopsia starts. Patients have normal both peripheral vision and dark adaptation. Combination of abnormal electro-oculography with normal classic full-field electroretinography is typical for this disease; however, even during the early stages, the macular flicker or multifocal electroretinogram may show reduced amplitudes in the central parts. There are four development stages in this disease [5]. There are no changes in the 1st stage within 10 years; visual acuity remains $20 / 20$ in $75 \%$ of persons. In the 2 nd and 3rd stages, for a large part there is advance within 5-10 yrs; visual acuity 20/40 or better in majority. In the 4 th stage, for the majority of patients there is no change over $5 \mathrm{yrs} ; 10 \%$ of $4 \mathrm{a}$ and $16 \%$ of $4 \mathrm{~b}$ progress to stage $4 \mathrm{c}$; visual acuity $20 / 20$ in 10\%; 19\% lose 2 lines or more in visual acuity over 8-10 yrs [6].

In this article, we are presenting a clinical case of the patient with the beginning of Best's vitelliform macular dystrophy.

\section{Case}

An 8-year-old boy was complaining of reduced visual acuity in the both eyes for several months. His medical and family history was unremarkable. There were no abnormalities found in the fundus of both eyes of his parents.

Snellen visual acuity in the right eye was 0.4 and 0.2 in the left eye. Cycloplegic refraction revealed hyperopia of $2.5 \mathrm{D}$ in the right eye and
$4.0 \mathrm{D}$ in the left. Full correction of refractive error improved visual acuity to 0.6 in the right eye and 0.3 in the left.

Slit lamp examination revealed normal anterior segments of the both eyes. We found small offuscation of the vitreous. Ophthalmoscopy of the right eye revealed a big yellow macular lesion surrounded by few smaller lesions with clear content and moderate retinal edema in the central part of the retina (similar to BVD "scrambled egg" stage) (Figure 1a). In the left eye we found a big round lesion with liquid boundary in the central part of the retina (similar to BVD pseudohypopyon stage) (Figure 1b). Peripheral retina was intact in both eyes.

Perimetry, dark adaptation and color sensitivity were normal. Longitudinal B scan ultrasound showed a lesion without prominence, with local edema in the central part of the retina in the right eye, and a lesion with diameter $0.68 \mathrm{X} 4.82 \mathrm{~mm}$ with small edema in the left eye.

Optical coherent tomography showed intraretinal and subretinal fluid accumulation in both eyes, retina swelling in the right eye, RPE/ chorioretinal complex was disrupted in some part of the central retina, between layers there was liquid accumulation. There was swelling of the retina in the left eye, the fovea shape was deformed between retinal pigment epithelium (RPE) neurosensorial part of the retina, abundant liquid accumulation was found in the RPE layer (changes are similar to Best vitelliform macular dystrophy). In the electro-oculogram Arden index of the right eye was 0.78 and 0.7 of the left eye (normal more than 1.8 (if $<1.8$; typical to BVD) in the electro-oculogram) (Figure 2). Waves $a$ and $b$ of the standard electroretinogram were normal (Figure 3 ).

Fluorescence angiography was not performed because of the patient's young age and allergy to fluorescein.

Correspondence to: Alvita Vilkeviciute, Lithuanian University of Health Sciences, Lithuania, Tel: +37062424461; E-mail: alvitavilkeviciute@gmail.com

Key words: best vitelliform macular dystrophy, case report, genetics

Received: April 15, 2017; Accepted: May 15, 2017; Published: May 18, 2017 


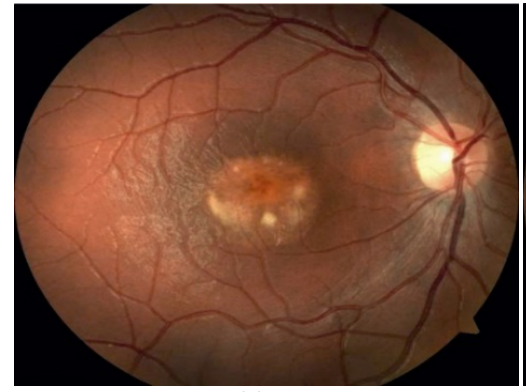

(a)

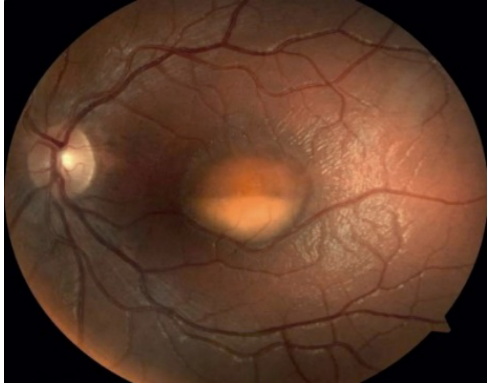

(b)

Figure 1. Ophthalmoscopy of the right eye (a) revealed a big yellow macular lesion surrounded by few smaller lesions with clear content and moderate retinal edema in the central part of the retina (similar to BVD "scrambled egg" stage). In the left eye (b) we found a big round lesion with liquid line in the central part of the retina (similar to BVD pseudohypopyon stage).

\section{Controls:}

FO: WiA. SO: A.dapt.DarkiAdapt.hight: 015015min.

Adaption times: 010 , Saccade tine: 1.5 sec

(View angle: $1 \mathrm{cleg}$. Ampitier: Freq. out ofts: $0.1-100 \mathrm{~Hz}$, Vmax $=+-2 \mathrm{mV}$ )

\section{SO Result:}

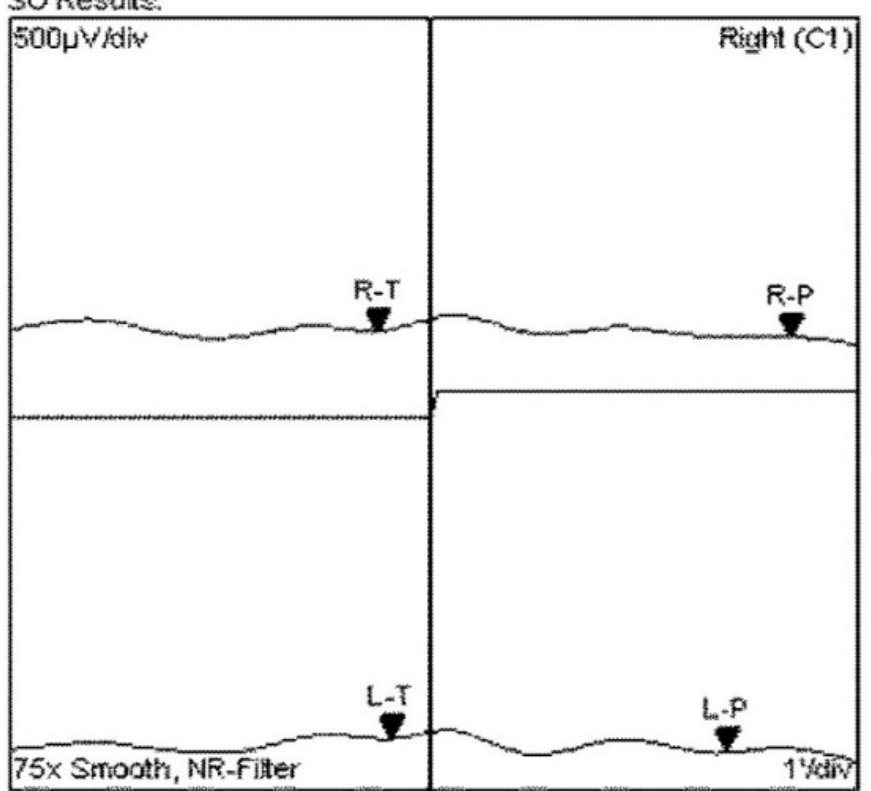

$\begin{array}{lll}\text { Values } & \text { Right } & \text { Left } \\ \text { So (Arden) } & 0.7846 & 0.7035 \\ \text { Peak } & 146.94 \mu^{\prime}-12^{\circ} 38^{\prime \prime} & 231.71 \mu^{\prime}-10^{\prime} 24^{\prime \prime} \\ \text { Trough } & 187.28 \mu \mathrm{V}-13^{\prime} 12^{\prime \prime} & 329.37 \mu \mathrm{V}-13^{\prime} 36^{\prime \prime}\end{array}$

Fight saccades:

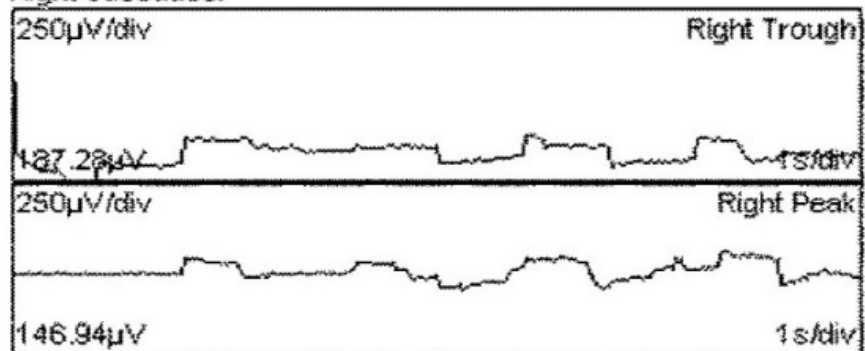

Left saccades:

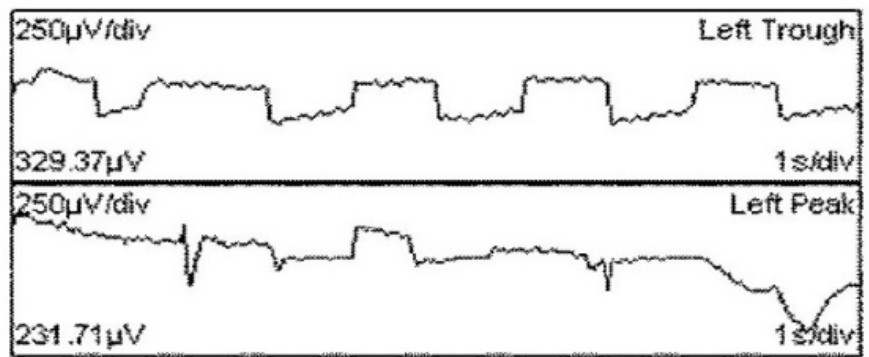

Diagnosis: - 1

Result: $+\frac{1}{-2}$

Figure 2. In the electro-oculogram Arden index of the right eye was 0.78 and 0.7 of the left eye.

We concluded that all examination data had confirmed Best vitelliform disease diagnosis. By sequencing of the BEST1 gene we detected a heterozygous mutation in exon 7 (c.728A $>$ T p.D243V). The patient's parents were examined and there were no vision abnormalities at all. Their visual acuity with the Snellen chart in the right eye was 1.0 and 1.0 in the left eye. There were no abnormalities found in the fundus of both parent. Perimetry, dark adaptation, longitudinal B-scan ultrasound, and color sensitivity were normal. ERG and EOG were also normal. Both parents of the patient tested negative at BEST1 sequencing, indicating that either a de novo mutation in the patient or germline mosaicism in one of the parents was possible (although no instances of germline mosaicism have been reported, it remains a possibility) [7].

\section{Discussion}

Best vitelliform macular dystrophy is a rare disease of unknown prevalence. Best disease is found in individuals of European, African, and Hispanic ancestry. It is inherited in an autosomal dominant pattern. BEST1 gene is responsible for the disease (11q12-q13) [8]. Most reported cases presented BEST1 gene with missense mutations in 

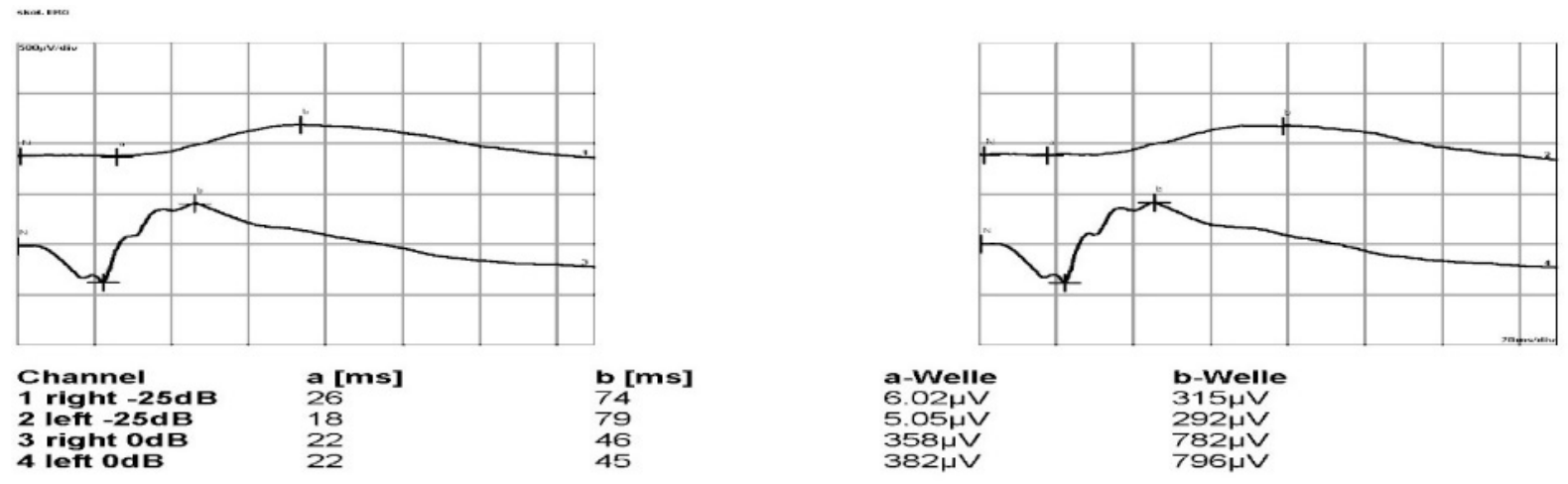

Group Values 1: Difference N: $-1 \mathrm{~ms}, \mathrm{a}: \mathbf{8 m s}, \mathrm{b}:-5 \mathrm{~ms}, \mathrm{a}-\mathrm{Welle:} 977 \mathrm{nV}, \mathrm{b}-\mathrm{Welle}: 22.8 \mu \mathrm{V}$
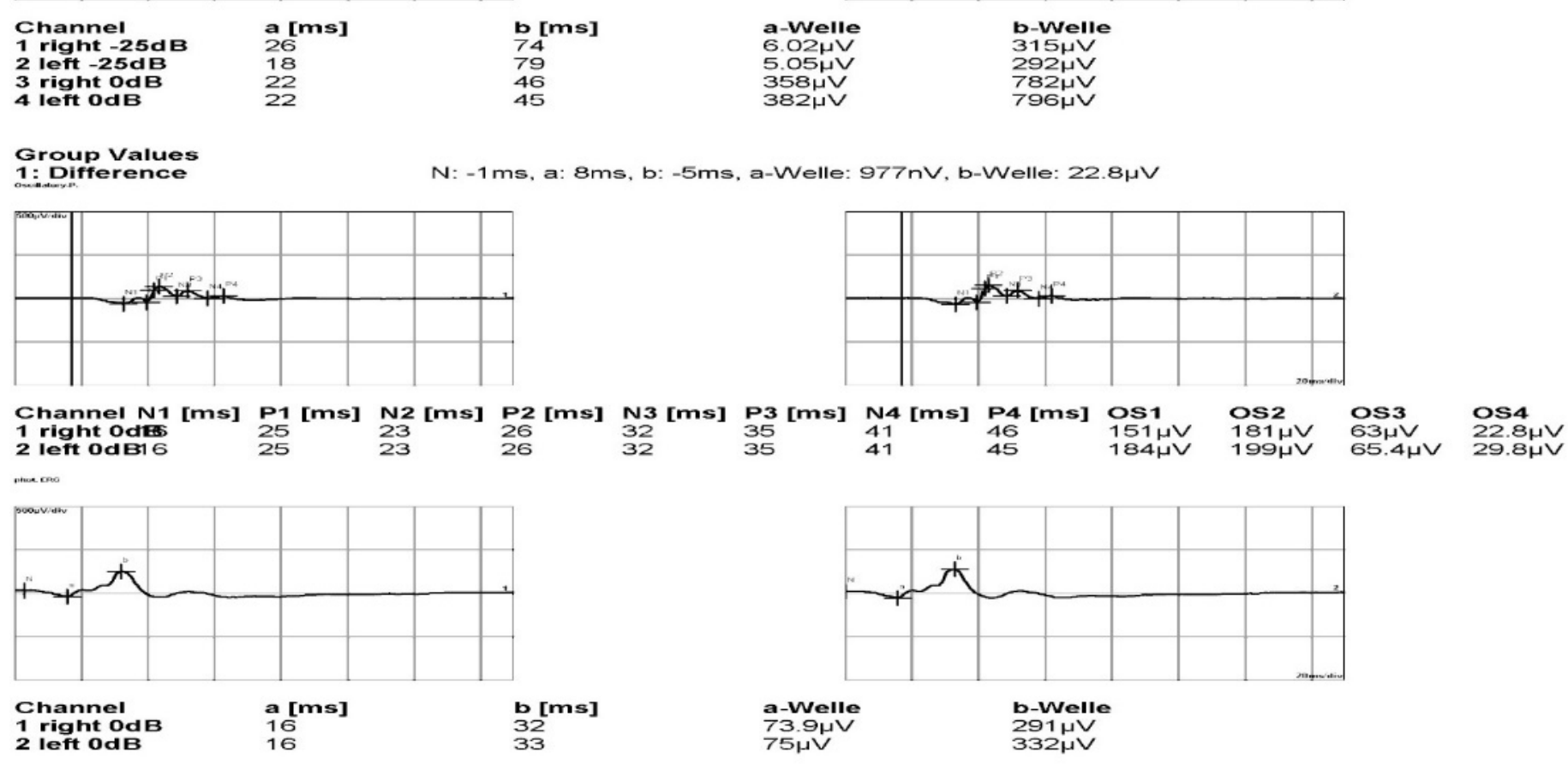

Group Values

1: Difference

$N$ : 3ms, a: Oms, b: -1 ms, a-Welle: $-1.14 \mu V, b-V$ Velle: $-41.2 \mu V$
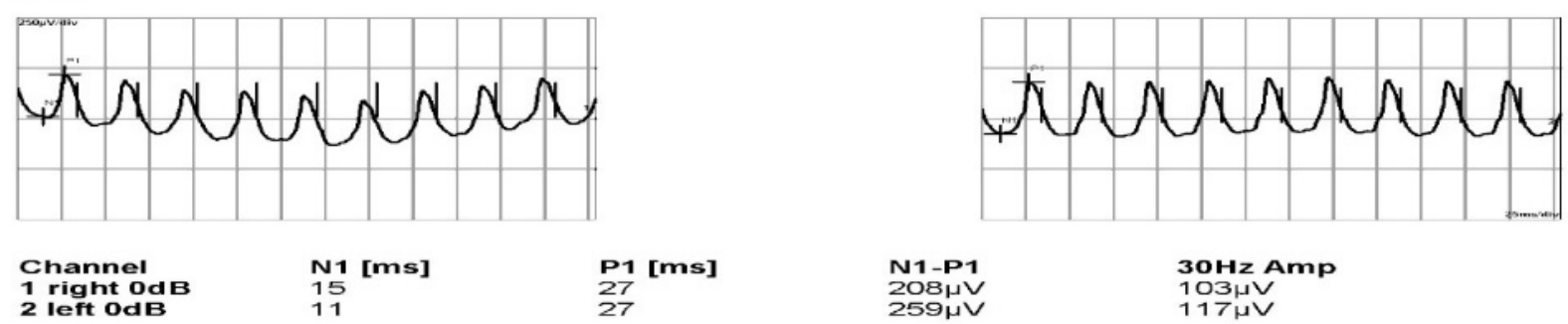

N1-P1
$208 \mu V$
$259 u v$

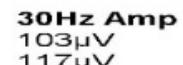

Figure 3. Waves a and $b$ of the standard electroretinogram were normal.

exons 2, 4, 6 and 8 causing the disease. In the presented case we found a new mutation in exon 7 of the BEST1 gene (c.728 $>$ T p.D243V). Such finding has been reported only in one case till now [9]. Mutations in BEST1 gene disturb the function of bestrophin and ion transport by the RPE, resulting in the accumulation of fluid between the RPE and the photoreceptors [10]. Usually Best disease starts at the age of 3-15 years, with mean age 6 years [11]. The visual acuity usually remains sufficient for many years, leaving the disease not detected until much later stages. The atrophic stage is generally observed in persons over 40 years old. Most patients suffering from Best vitelliform macular dystrophy have a parent with this condition, however, the disease can also be caused by de novo mutation [12]. Although no instances of germline mosaicism have been reported, there still remains a possibility when parents test negative [7] Best disease diagnosis is based on electro-oculogram abnormalities (abnormalities observed even in asymptomic patients).
Other tests, like fluorescein angiography which is contraindicated till 12 years, RPE autofluorescence, optical coherence tomography, full-field and multifocal electroretinogram (ERG), might provide additional information for the correct diagnosis. Many individuals with Best disease initially do not feel any symptoms, but fundus lesions are noted on examination. Visual symptoms can include decreased acuity (blurring) and metamorphopsia. They may worsen if the disease progresses to the atrophic stage $[6,13,14]$.

Best disease needs to be differentiated from the other distrophies of the central part of the retina and choroid: Stargardt macular dystrophy, central oreolar pigment epithelium dystrophy, cone dystrophy, Sorsby fundus dystrophy, North Carolina macular dystrophy, fundus flavimaculatus, foveal changes in angioid steaks, age-related macular degeneration, Malattia Levantinese, retinopathia centralis serosa, 
central chorioretinitis, serous retinal pigment epithelium detachment, colobomas of the central retina. [15].

There is no causal treatment of this disorder. The management includes support concerning school or activities of patients. For treatment of choroidal neovascularization (CNV), anti-VEGF (vascular endothelial growth factor) agents such as bevacizumab are used increasingly. [16]. However, long-term follow-up of these patients is unknown and there are currently no clinical trials to demonstrate the effectiveness of anti-VEGF agents. Andrade et al. used verteporfin in photodynamic therapy (PDT) for subfoveal choroidal neovascularization in one person with Best vitelliform macular dystrophy [17]. The CNV regressed and the subretinal hemorrhage resolved. The authors suggested that PDT might be an option for treatment of CNV in Best vitelliform macular dystrophy [17].

\section{Conclusion}

We found a heterozygous mutation in exon 7 of the BEST1 gene (c.728A $>$ T p.D243V), and we concluded that the patient is very likely to suffer from BVD, due to a mutation in the BEST1 gene.

\section{Acknowledgments}

We are very thankful to Centogene $\mathrm{GmbH}$ (The rare disease company) for gene mutation diagnosis for this family.

\section{References}

1. Best F. Ueber eine herediaere Macular affection. Z. Augenheilk (1905) 13:199-212.

2. Deutman AF. The Hereditary Dystrophies of the Posterior Pole of the Eye. Assen, the Netherlands: Van Gorcum \& Co (1971): 198-299.

3. Lotery AJ, Munier FL, Fishman GA, Weleber RG, Jacobson SG, et al. (2000) Allelic variation in the VMD2 gene in best disease and age-related macular degeneration. Invest Ophthalmol Vis Sci 41: 1291-1296. [Crossref]

4. Remky h, Rix j, Klier kf (1965) Dominant-autosomal macular degeneration (best, sorsby) with cystic and vitelliform stages (huysmans, zanen). Klin Monbl Augenheilkd 146: 473-497. [Crossref]
5. Mohler CW, Fine SL (1981) Long-term evaluation of patients with Best's vitelliform dystrophy. Ophthalmology 88: 688-692. [Crossref]

6. Fishman GA, Baca W, Alexander KR, Derlacki DJ, Glenn AM, et al. (1993) Visual acuity in patients with best vitelliform macular dystrophy. Ophthalmology 100: 16651670. [Crossref]

7. MacDonald IM, Lee T.Best Vitelliform Macular Dystrophy. [Crossref]

8. Stöhr H, Marquardt A, Rivera A, Cooper PR, Nowak NJ, et al. (1998) A gene map of the Best's vitelliform macular dystrophy region in chromosome 11q12-q13.1. Genome Res 8: 48-56. [Crossref]

9. Low S, Davidson AE, Holder GE, et al. (2011) Autosomal dominant Best disease with an unusual electrooculographic light rise and risk of angle-closure glaucoma: a clinical and molecular genetic study. Mol Vis 17: 2272-82. [Crossref]

10. Hartzell HC, Qu Z, Yu K, et al. (2008) Molecular physiology of bestrophins multifunctional membrane proteins linked to best disease and other retinopathies. Physiol Rev 88: 639-72. [Crossref]

11. François J, De Rouck A, Fernandez-Sasso D (1967) Electro-oculography in vitelliform degeneration of the macula. Arch Ophthalmol 77: 726-733. [Crossref]

12. Testa F, Rossi S, Passerini I, et al. (2008) A normal electro-oculography in a family affected by best disease with a novel spontaneous mutation of the BEST1 gene. $B r J$ Ophthalmol 92:1467-70. [Crossref]

13. Marano F, Deutman AF, Leys A, Aandekerk AL (2000) Hereditary retinal dystrophies and choroidal neovascularization. Graefes Arch Clin Exp Ophthalmol 238: 760-764. [Crossref]

14. Mohler CW, Fine SL (1981) Long-term evaluation of patients with Best's vitelliform dystrophy. Ophthalmology 88: 688-692. [Crossref]

15. Besch D, Zrenner E (2005) Best disease. Orphanet Encyclopedia. 1-5.

16. Leu J, Schrage NF (2007) Degenring RF. Choroidal neovascularisation secondary to Best's disease in a 13-year-old boy treated by intravitreal bevacizumab. Graefes Arch Clin Exp Ophthalmol 245:1723-5. [Crossref]

17. Andrade RE, Farah ME, Costa RA (2003) Photodynamic therapy with verteporfin for subfoveal choroidal neovascularization in best disease. Am J Ophthalmol 136: 11791181. [Crossref]

Copyright: (C2017 Vilkeviciute A. This is an open-access article distributed under the terms of the Creative Commons Attribution License, which permits unrestricted use, distribution, and reproduction in any medium, provided the original author and source are credited. 